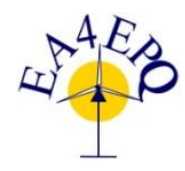

INTERNATIONAL CONFERENCE ON RENEWABLE ENERGIES AND POWER QUALITY (ICREPQ'18)

Salamanca (Spain), $21^{\text {th }}$ to $23^{\text {th }}$ March, 2018

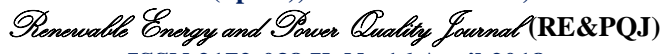

ISSN 2172-038 X, No.16 April 2018

\title{
Controller Design Based on Internal Model Applied in a Quadratic Boost Converter with P\&O MPPT
}

\author{
E. N. Chaves ${ }^{1}$, G. P. Viajante ${ }^{1}$, M. A. A. Freitas ${ }^{1}$, L. S. Villefort ${ }^{2}$, H. T. de Moura ${ }^{2}$, L. C. G. de Freitas ${ }^{2}$, E. A. A. \\ Coelho $^{2}$ \\ ${ }^{1}$ Federal Institute of Education, Science and Technology of Goiás. \\ Energy Systems Research Center (Núcleo de Pesquisas em Sistemas de Energia - NuPSE) \\ Phone/Fax number: 5564 343152005, e-mail A: eric.chaves@ifg.edu.br \\ ${ }^{2}$ Electric Drives Laboratory, Federal University of Uberlândia \\ Campus Santa Mônica, Uberlândia-MG, Brasil. \\ Phone/Fax number: 5534 3239-4411, e-mail: B. ernane@ufu.br
}

\begin{abstract}
This paper presents the controller design used in the inner loop of the Perturb and Observe $(\mathrm{P} \& \mathrm{O})$ type of maximum power point tracking (MPPT) algorithm to control the output voltage of photovoltaic panels, from a DC-DC quadratic boost converter. The use of such a converter is based on the need to extend the DC-DC conversion range and acquire a quadratic dependence of the output voltage in relation to the duty cycle. In order to investigate a method that improves the controllability of this DC-DC converter, the design of an internal model based controller with 1 degree of freedom is proposed, and its performance is evaluated through experimental results that support the viability of its application.
\end{abstract}

\section{Keywords}

Internal Model Control, Maximum Power Point Tracking, Photovoltaic Generation, Quadratic Boost Converter.

\section{Introduction}

For most grid-connected photovoltaic systems, a converter that performs Maximum Power Point Tracking (MPPT) of the series and/or parallel arrangement of solar panels is necessary [1]. The converter most commonly used for such applications is the DC-DC boost converter. However, the static gain of the boost converter is limited due to conduction losses suffered when the duty cycle $(D)$ approaches that of the unity [2]. By keeping in mind the need to amplify the operating band of DC-DC converters, a quadratic boost converter is presented in [3]. The voltage gain for this converter has a quadratic dependence on duty cycle (D). Other converter topologies with the same features were presented in [4] and [5].

Following on with the line of research for this converter, different control techniques were presented as in [6]-[12]. In these studies, where proposals for control methods of quadratic boost converters are made, the technical difficulties for controlling this DC-DC converter are presented. However, in these studies, as in many others for this converter, control methods for non-MPPT applications are developed.

The quadratic boost converter is characterized through it being a fourth order system. In addition, when this system is modelled for the input voltage control of the converter, typical of MPPT algorithms, its dynamic is marked by the presence of complex conjugate poles close to the imaginary axis of s-plane, and two complex conjugate zeros in the right half-plane. These invert the time response of the system, when under the influence of such compensators.

Therefore, the aim herein is to investigate a method that improves the controllability of this DC-DC converter in MPPT applications. Thus, this paper puts forward a proposal for a control design based on Internal Model Control with one degree of freedom (1-DOF IMC) applied to the quadratic boost converter.

Its performance is evaluated through experimental results, where the corroboration of its viability for MPPT application is sought, according to the needs of a system that can be connected to the grid with respect to the voltage value for the DC bus. Figure 1 presents the structure of the system involving the MPPT, P\&O (Perturb and Observe) and the IMC controller, together with the quadratic boost DC-DC converter.

\section{Modelling of the Quadratic Boost Converter for the Input Voltage Control}

In order to design the controller, the modelling process of the quadratic boost converter was performed through use of state-space averaging [13]. 


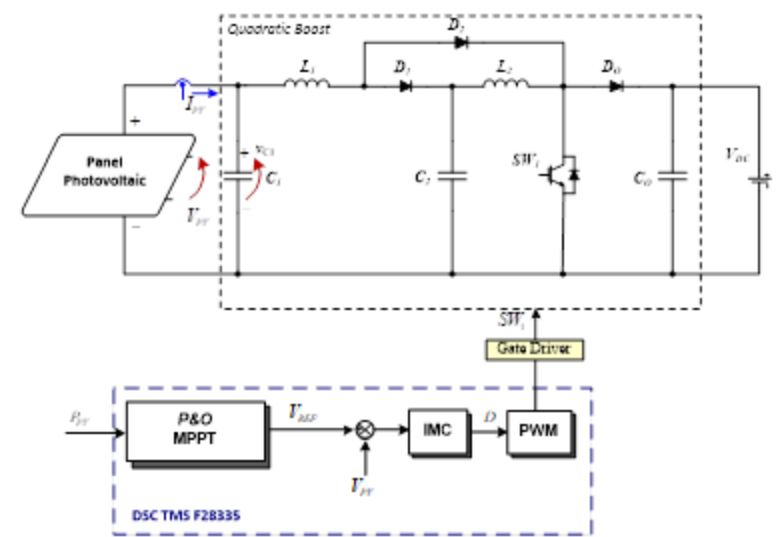

Fig. 1. Structure for the system involving the MPPT, the IMC controller and the quadratic boost converter.

This modelling presented for the first time in [14], and was developed as a technique that allows for the obtainment of a variable model of state-space averaging. This results in a valid linear model for small disturbances, through linearization around an operational point.

For the modelling of the quadratic boost converter operating as a maximum power tracker for a photovoltaic arrangement, the converter circuit should be analysed as shown in Figure 2. One notes from this Figure that the output voltage on the DC bus is considered fixed $\left(V_{D C}\right)$, being that the converter input voltage $\left(V_{P V}=v_{c l}\right)$ should be controlled by a control logic defined by the maximum power point tracking algorithm $\mathrm{P} \& \mathrm{O}-\mathrm{MPPT}$.

The $R_{P V}$ resistor represents the equivalent output resistance for the photovoltaic arrangement, which itself is linked to the output voltage variations $\left(V_{P V}\right)$ along with its current $\left(I_{P V}\right)$. The model of the photovoltaic cell is described in [1], and is implicit when using $R_{P V}$ for modelling the panel or arrangement of photovoltaic panels from its electrical output characteristics [1].

In this manner, the model of the panel on the quadratic boost converter system is included, and as a simplification, it is assumed that $I_{P V}$ (and its variation) is a disturbance, since its intention is to control the $V_{P V}$.

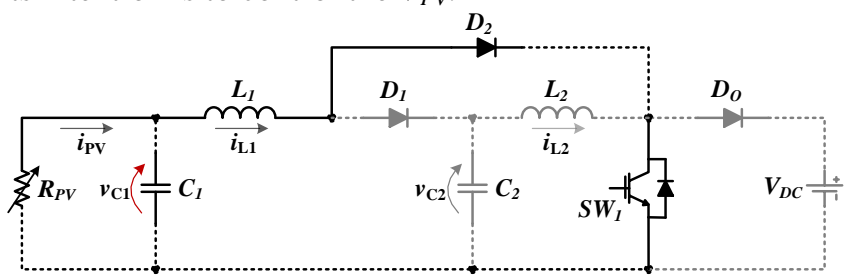

(a)

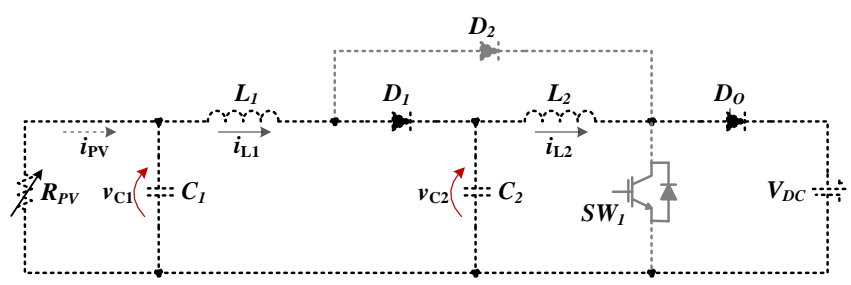

(b)

Fig. 2. Converter stages on the two switching intervals.
To perform the mathematical modelling, two stages associated with the converter were considered at each switching interval. Figure 2 presents the scheme for these two stages. During stage 1, shown in Figure 2(a), switches $S W_{l}$ and $D_{2}$ remain closed and $D_{l}$ and $D_{0}$ open. In stage 2, Figure 2(b), switches $S W_{l}$ and $D_{2}$ remain open and $D_{1}$ and $D_{0}$ closed.

In this fashion, the converter can be described by linear state equations such as,

$$
\begin{aligned}
& \dot{x}=A_{1} x(t)+B_{1} u(t) \\
& \dot{x}=A_{2} x(t)+B_{2} u(t)
\end{aligned}
$$

where,

$$
x=\left[\begin{array}{l}
i_{L 1} \\
i_{L 2} \\
v_{C 1} \\
v_{C 2}
\end{array}\right] \text { and } u(t)=V_{D C}
$$

The dynamic arrays for each stage of the operation are given respectively by,

$A_{1}=\left[\begin{array}{cccc}0 & 0 & \frac{1}{L_{1}} & 0 \\ 0 & 0 & 0 & \frac{1}{L_{2}} \\ -\frac{1}{C_{1}} & 0 & -\frac{1}{R_{P V} C_{1}} & 0 \\ 0 & -\frac{1}{C_{2}} & 0 & 0\end{array}\right] \quad A_{2}=\left[\begin{array}{cccc}0 & 0 & \frac{1}{L_{1}} & -\frac{1}{L_{1}} \\ 0 & 0 & 0 & \frac{1}{L_{2}} \\ -\frac{1}{C_{1}} & 0 & -\frac{1}{R_{P V} C_{1}} & 0 \\ \frac{1}{C_{2}} & -\frac{1}{C_{2}} & 0 & 0\end{array}\right]$

The input arrays for each stage of the operation are given respectively by,

$$
B_{1}=\left[\begin{array}{l}
0 \\
0 \\
0 \\
0
\end{array}\right] \quad B_{2}=\left[\begin{array}{c}
0 \\
-\frac{1}{L_{2}} \\
0 \\
0
\end{array}\right]
$$

If one considers that the converter operates in the continuous conduction mode (CCM), the dynamics and input arrays can be represented by the average values,

$$
A_{\text {med }}=A_{1} D+A_{2}(1-D) \quad B_{\text {med }}=B_{1} D+B_{2}(1-D)
$$

To perform linearization, one should obtain the point of operation in steady state, where the derivatives for the state variables become zero. Thus it is possible to obtain the average values for the state variables by,

$$
X_{\text {med }}=-A_{\text {med }}^{-1} B_{\text {med }} V_{D C}
$$

Which becomes [13],

$$
B_{d}=\left[A_{1}-A_{2}\right] X_{\text {med }}+\left[B_{1}-B_{2}\right] V_{D C}
$$

through applying the small signals model to the average state space equation and making the necessary simplifications, then one follows by applying the Laplace transform to the equation, which results in,

$$
\hat{X}(s)=\left(s I-A_{\text {med }}\right)^{-1}\left[B_{\text {med }} \hat{U}(s)+B_{d} \hat{D}(s)\right]
$$


Therefore, the transfer functions of the state variable disturbances in relation to disturbances on the duty cycle $D$ will result in,

$G_{x d}(s)=\frac{\hat{X}(s)}{\hat{D}(s)}=\left(s I-A_{\text {med }}\right)^{-1} B_{d}$

As one desires to control the converter input voltage, with the aim of extracting the maximum power from the photovoltaic arrangement, the transfer function used will therefore be,

$\hat{G}_{v_{C 1} / d}=\frac{V_{D C} a}{R_{P V}+b s+c s^{2}+d s^{3}+e s^{4}}$

On which,

$$
\begin{aligned}
& a=(1-D)\left[2 R_{P V}-L_{2}(1-D)^{2} s+\left(R_{P V} C_{2} L_{2}\right) s^{2}\right] \\
& b=\left[L_{1}+L_{2}(1-D)^{2}\right] \\
& c=\left[R_{P V}\left(C_{1} L_{1}+C_{2} L_{2}+C_{1} L_{2}(1-D)^{2}\right)\right] \\
& d=\left(C_{2} L_{1} L_{2}\right) \\
& e=\left(R_{P V} C_{1} C_{2} L_{1} L_{2}\right)
\end{aligned}
$$

\section{Specifications for the Quadratic Boost Converter}

The quadratic boost converter was designed to perform the maximum power tracking of a photovoltaic arrangement and increase the voltage to $350 V_{C C}$.

However, details for this design are not provided here, as it is not the focal point of the present study. Nevertheless, the parameters used for the converter in question are presented on Table I. $D=50 \%$ provides the static gain appropriate to the application. Therefore, the system has been linearized at this point of operation around which the controller operates.

Further, it is assumed that the parameter denominated $R_{P V}$, illustrated in Figure 2, a component in the model of the system defined in (11), travels along a range that goes from $17 \Omega$ to $85 \Omega$. This corresponds to an output power range for the photovoltaic panels that goes from approximately $200 \mathrm{~W}$ to $1000 \mathrm{~W}$. These data were obtained via computer simulations from the simplified model with an exponential [1], and verified through experiments using the photovoltaic panel arrangement installed in the laboratory.

Table I - Parameters of the Quadratic Boost

\begin{tabular}{lll} 
Parameters & Name & Value \\
\hline Input Capacitance & $C_{I}$ & $4,7 \mu \mathrm{F}$ \\
\hline Filter Capacitance & $C_{2}$ & $4,7 \mu \mathrm{F}$ \\
\hline Output Capacitance & $C_{O}$ & $330 \mu \mathrm{F}$ \\
\hline Input Inductance & $L_{l}$ & $950 \mu \mathrm{H}$ \\
\hline Filter Inductance & $L_{2}$ & $2,0 \mathrm{mH}$ \\
\hline Output Voltage (Inverter DC Bus) & $V_{D C}$ & $350 \mathrm{~V}$ \\
\hline Duty Cycle & $D$ & $50 \%$ \\
\hline Switching Frequency & $f_{S}$ & $60 \mathrm{kHz}$ \\
\hline
\end{tabular}

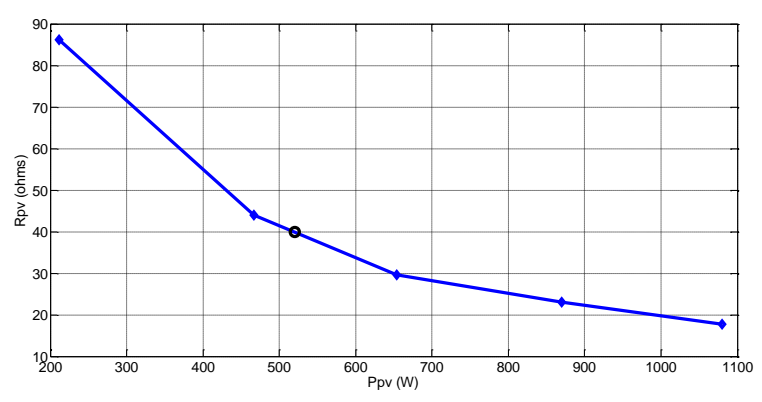

Fig. 3. Variation of the output parameters of the photovoltaic arrangement.

\section{Internal Model Control}

The term Model Based Control MBC is used to design control systems that explicitly incorporate a process model into the control algorithm, in particular control algorithms, such as Internal Model Control - IMC and Model-Predictive Control - MPC [15].

Figure 4 presents in generic form a control strategy based on the internal model with one degree of freedom (1-DOF IMC), in which $p(s)$ is the process, $\tilde{p}(s)$ is the process model, $u(s)$ is the control effort, $d(s)$ is the disturbance, and $\tilde{d}_{e}(s)$ is the estimated disturbance [15].

Since the process model $\tilde{p}(s)$ is a perfect representation of the stable process $p(s)$, if the controller $q(s, \varepsilon)$ gain is the inverse of the model gain, then the process output $y(s)$ will eventually reach and maintain the reference $r(s)$, that is if the process gain and model gain have the same signal, and the controller is tuned in a way that assures stability. The model is therefore, a linear transfer function and the controller is approximately the inverse of the transfer function of the model.

From the input-output relationships outlined in Figure 4 it can be inferred that,

$$
y(s)=\frac{p(s) q(s) r(s)}{1+(p(s)-\tilde{p}(s)) q(s)}
$$

and

$$
y(s)=\frac{(1-\tilde{p}(s) q(s)) p_{d}(s) d(s)}{1+(p(s)-\tilde{p}(s)) q(s)}
$$

Where $p_{d}(s)$ is the model of the system in virtue of the disturbance, or be it, the effect of the disturbance flows through the system and is added to the system output.

Through the application of the final value theorem, if (17) and (18) are dynamically stable, and if the controller system gain $q(0)$ is chosen to be the inverse of the internal model gain $(\tilde{p}(0) q(0)=1)$, then the gain for the denominator of $(17)$ and (18) will be $p(0) q(0)$. Therefore, the direct path gain, i.e. between the reference $r(s)$ and the output $y(s)$ is one, the gain between the disturbance and $y(s)$ is zero, and the steady state error is zero. 


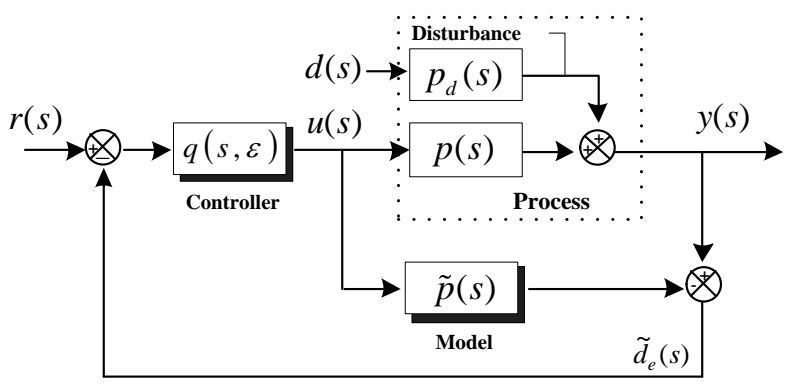

Fig. 4. Control structure based on 1-DOF IMC.

The core concept of this control strategy is to achieve,

$y(s)=r(s) \quad y(s) / d(s)=0$

Since,

$p(s) q(s)=1 \quad \tilde{p}(s)=p(s)$

However, in order that the control action is efficient in tracking the reference, a perfect model is necessary, and for (20), the controller should be the perfect inverse to this model [15]. Hence, one never reaches an exact model, and if this model has some form of dynamic (a more common fact), no controller can invert the process exactly [16]. How close it gets to the dynamic of the real process, will depend on the design of the controller.

\section{A. Design of the IMC-1DOF Controller}

By use of the criteria covered in [15] for the design of these controllers, when the transfer function of the process, defined in (11) and with the parameters listed in Table I, has zeros on the right half plane and $s$ plane, its inverse is not stable. In this case the IMC controller cannot be formed from a simple cancelling of poles with zeros, as in the original controller design.

For these cases, by considering the minimization method of the integral of the squared error (ISE), when it comes to the optimal choice of IMC IDOF controller, the controller design consists of inverting this part of the model that contains zeros on the left half plane and add poles on the mirrored image of the zeros right half plane of the $s$ plane [17]. Therefore, the 1-DOF IMC controller for the input voltage control of the quadratic boost converter $\left(V_{P V}=v_{c l}\right)$, can be designed as,

$$
q(s)=\frac{D(s)}{N_{-}(s) N_{+}(s)(\varepsilon s+1)^{r}}
$$

Where, $N(s)$ is the polynomial of the numerator and $D(s)$ the polynomial of the transfer function denominator, as described in (11) and the corresponding process $p(s)$, and $r$ is defined as the difference between the order of the denominator minus the numerator order of the transfer function. In addition, $N_{-}(s)$ contains numerator factors of the transfer function that presents zeros on the left half plane of the $s$ plane, and $N_{+}(s)$ contains the numerator factors of the transfer function of the system that presents zeros on the right half plane of the $s$-plane. However, the factors of $N_{+}$ will be positioned on the left half plane of the $s$-plane and will be the mirrored images of the zeros of $N_{+}$. The factor involving $\varepsilon$ makes $q(s)$ casual and thus, physically realizable, being that $\varepsilon$ is a parameter that defines the cut off frequency of the open loop gain for the compensated system. For the design of the 1-DOF IMC controller, the term $\varepsilon$ can be calculated in accordance with [15], from,

$$
\varepsilon \geq\left(\lim _{s \rightarrow \infty} \frac{D(s) N(0)}{20 s^{r} N(s) D(0)}\right)^{1 / r}
$$

where the maximum gain allowed in high frequency has its value arbitrated at 20 times the gain in low frequency. However, even when considering (22), better results were obtained by maintaining the value of $\varepsilon$ at 0.0003 .

\section{Experimental Results}

To perform the experiment involving the use of the quadratic boost converter on the tracking of the maximum power point, through use of the $\mathrm{P} \& \mathrm{O}$ algorithm, the 1-DOF IMC controller, $q(s)$, defined in (21), was discretized by the Tustin method and the internal model $\tilde{p}(s)$, the transfer function defined in (11), used in the composition of the 1DOF IMC structure, this was discretized by the $\mathrm{ZOH}$ method. All these were implemented with a sampling rate of $20 \mathrm{kHz}$, and embedded on the DSC TMS320F28335 from Texas Instruments ${ }^{\circledR}$. The tests were performed using the photovoltaic panel emulator E4360A, from Agilent, onto which the data from the two Yingli panels model YL245P29B (of $245 \mathrm{~W}$ each) were programmed. These data originated from irradiance and temperature profiles, in a manner that they had varying steps between distinct power points. These programming data from the emulator are presented on Table II. Figure 19 shows the output current from the emulator $\left(I_{P V}\right)$ and the power $\left(P_{P V}\right)$ being extracted and delivered to a resistive load in parallel with the DC bus.

The load, therefore, has voltage source characteristics. To get a better understanding, the update rate from the $\mathrm{P} \& \mathrm{O}$ was fixed at $50 \mathrm{~Hz}$ and the emulator was programmed with the data referring to irradiance of $800 \mathrm{~W} / \mathrm{m}^{2}$, as presented on table II. One notes that in this result, the power ripple caused by the voltage disturbance $V_{P V}$ and the 1-DOF IMC controller action, maintains the time response along with a rapid stability on the new voltage level.

Table II - Data programmed onto the E4360A.

\begin{tabular}{l|l|l|l|l|l}
\hline \multicolumn{4}{|l|}{ 2 Panels YL245P-29B IN SERIES } & \\
\hline $\boldsymbol{W} / \boldsymbol{m}^{\mathbf{2}}$ & $\boldsymbol{I m p}(\boldsymbol{A})$ & $\boldsymbol{I} \boldsymbol{s c}(\boldsymbol{A})$ & $\boldsymbol{V m p}(\boldsymbol{V})$ & $\operatorname{Voc}(\boldsymbol{V})$ & $\operatorname{Pmax}(\boldsymbol{W})$ \\
\hline 1000 & 8.18 & 8.74 & 59.91 & 74.7 & 490 \\
\hline 800 & 6.52 & 7.00 & 60.35 & 74.28 & 394 \\
\hline 300 & 2.42 & 2.62 & 59.84 & 71.12 & 145 \\
\hline 100 & 0.79 & 0.87 & 57.36 & 67.54 & 45.3 \\
\hline 25 & 0.38 & 0.43 & 27.64 & 32.6 & 10.5 \\
\hline
\end{tabular}




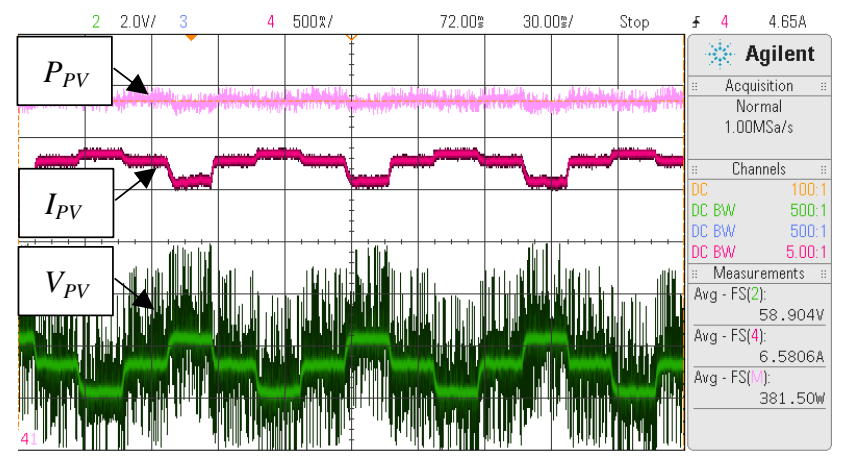

Fig. 5. Voltage $\left(V_{P V}\right)$ in steps of $1 \mathrm{~V}$, the current $\left(I_{P V}\right)$ and power $\left(P_{P V}\right)$. Scale: $\mathrm{Ch} 2\left(V_{P V}\right) 2.0 \mathrm{~V} / \mathrm{div}$, zero level $63.675 \mathrm{~V}$; Ch4 $\left(I_{P V}\right)$ $500 \mathrm{~mA} / \mathrm{div}$, zero level $5.8187 \mathrm{~A}$; Time $30 \mathrm{~ms} / \mathrm{div}$.

Figure 20 shows the voltage on the terminals of the emulator $\left(V_{P V}\right)$, as it is disturbed by the $\mathrm{P} \& \mathrm{O}$ in $2.0 \mathrm{~V}$ steps, along with emulator output current $\left(I_{P V}\right)$ and the power extracted from it $\left(P_{P V}\right)$. To perform this test, the device was programmed with the data referring to irradiance of 800 $\mathrm{W} / \mathrm{m}^{2}$. Noted in this result is the fact that there exists an increase in the amplitude of the power ripple, caused by the disturbance of the voltage $V_{P V}$.

The conclusion was reached, through experiment, that this increase in the amplitude of the power ripple compromises the power efficiency of the system. Noteworthy also is the action from the 1-DOF IMC controller, which maintains the response from the voltage $\left(V_{P V}\right)$ with a rapid stabilization, even though it presents a certain overshoot level.

Figures 21 and 22 show the voltage on the terminals of the emulator for the photovoltaic panel arrangement $\left(V_{P V}\right)$, as it is disturbed by the $\mathrm{P} \& \mathrm{O}$ in steps of $0.5 \mathrm{~V}$, the output current $\left(I_{P V}\right)$ and the power $\left(P_{P V}\right)$. To perform the test in Figure 21, the emulator was programmed with the irradiance reference data of $25 \mathrm{~W} / \mathrm{m}^{2}$.

However, in the test shown in Figure 22, it was programmed with the data referring to an irradiance of 1000 $\mathrm{W} / \mathrm{m}^{2}$ (data from Table II).

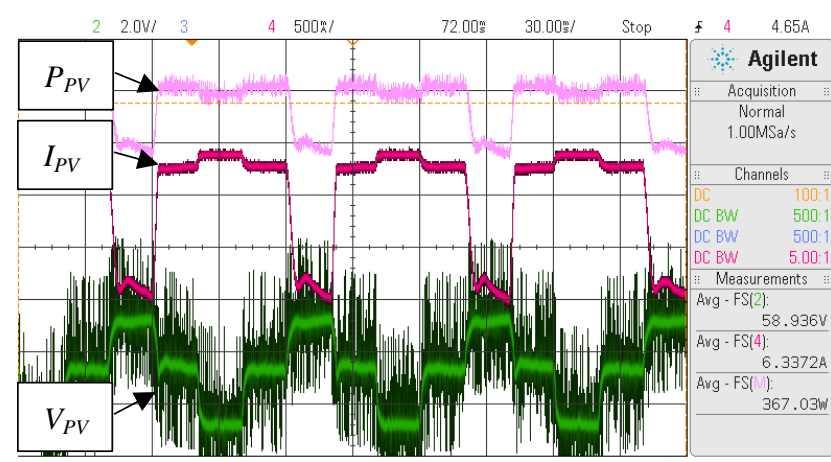

Fig. 6. Voltage $\left(V_{P V}\right)$ in steps of $2 \mathrm{~V}$, the current $\left(I_{P V}\right)$ and power $\left(P_{P V}\right)$. Scale: $\mathrm{Ch} 2\left(V_{P V}\right) 2.0 \mathrm{~V} / \mathrm{div}$, zero level $63.675 \mathrm{~V} ; \mathrm{Ch} 4\left(I_{P V}\right)$ $500 \mathrm{~mA} /$ div, zero level $5.8187 \mathrm{~A}$; Time $30 \mathrm{~ms} / \mathrm{div}$.

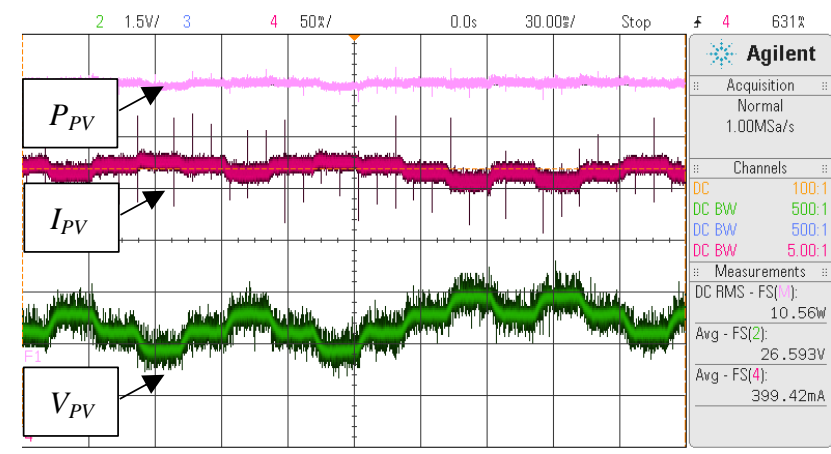

Fig. 7. Voltage $\left(V_{P V}\right)$ in steps of $0.5 \mathrm{~V}$, the current $\left(I_{P V}\right)$ and power $\left(P_{P V}\right)$. Scale: $\mathrm{Ch} 2\left(V_{P V}\right) 1.5 \mathrm{~V} / \mathrm{div}$, zero level $29.0 \mathrm{~V}$; Ch4 $\left(I_{P V}\right) 50$ $\mathrm{mA} /$ div, zero level $330.625 \mathrm{~mA}$; Time $30 \mathrm{~ms} / \mathrm{div}$.

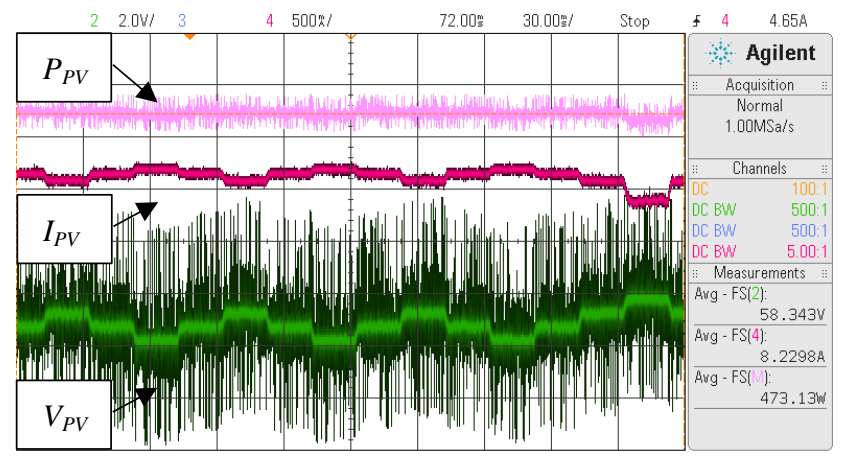

Fig. 8. Voltage $\left(V_{P V}\right)$ in steps of $0.5 \mathrm{~V}$, the current $\left(I_{P V}\right)$ and power $\left(P_{P V}\right)$. Scale: $\mathrm{Ch} 2\left(V_{P V}\right) 2.0 \mathrm{~V} / \mathrm{div}$, zero level $61.5 \mathrm{~V}$; Ch4 $\left(I_{P V}\right) 500$ $\mathrm{mA} /$ div, zero level $7.6 \mathrm{~A}$; Time $30 \mathrm{~ms} /$ div.

One notes from these results, a decrease in the amplitude of the power ripple, which produces an almost imperceptible wave. Through experiment it was demonstrated that this decrease in power ripple amplitude improves the power efficiency of the system.

Highlighted herein is the point that the action of the 1-DOF IMC controller maintains the time response of the voltage $\left(V_{P V}\right)$ with a rapid stability and performance similar across the available power extremes.

\section{Conclusions}

Some conclusions can be drawn from the development of the study into the application of the DC-DC quadratic boost converter. During the processing of power generated by a photovoltaic panel arrangement, together with the tracking algorithm of the highest power point, the P\&O-MPPT for which the variable is disturbed, shows that the voltage on the terminals of the arrangement $\left(V_{P V}\right)$, was in fact being controlled by the 1-DOF IMC.

Firstly, given the difficulties in controlling the plant in virtue of its dynamic, the 1-DOF IMC compensator was able to fully operate in the internal loop of the MPPT algorithm, which adequately controls the variable of interest $\left(V_{P V}\right)$. In terms of performance, it exhibited an excellent response time in a system that needs to be fast in accordance with the variation of the temporal luminance standard. Therefore, 
making it apt for contributing toward the increase of the power efficiency of this system.

However, the option of maintaining the parameter $R_{P V}$ fixed, on the transfer function defined in (13), and through this the coefficients are also fixed for $q(s)$, and its discrete versions, accumulated in a small overshoot in some experimental results. This was in fact due to the value of $R_{P V}$, which varies according to luminance and temperature.

However, this overshoot was only noted through the step in $\mathrm{V}_{\text {Ref }}$ fixed at $2.0 \mathrm{~V}$ and when the system is operating close to the power extremes of the photovoltaic arrangement. This consequently means operating with the effective value $R_{P V}$ further from the value that was used in the 1-DOF IMC controller design. Hence, the accommodation time for the controlled variable is rapid and the steady state error is nil, thus aligning this controller in a manner where it is viable and adequate to this control application for the closed loop of the P\&O-MPPT algorithm, together with the DC-DC quadratic boost converter.

Regarding the DC-DC converter, the experimental tests confirm its viability in this type of application, when dealing with the area of MPP tracking and the maintenance of an adequate voltage level on the DC bus.

A mention should be given regarding the size of the P\&OMPPT step. The step, for which the voltage value is large $(2.0 \mathrm{~V})$ showed that the convergence velocity for the MPP increases. This however, in effect has a price which is paid on the amplitude increase of the power ripple, thus decreasing the power efficiency of the system. Better results, involving a compromise between efficiency and rapid response was obtained with a step value of $0.5 \mathrm{~V}$.

Finally, the system as a whole was capable of operating on the MPP, even when faced with large amplitude power steps. In other words, even with the plant varying greatly and rapidly, the 1-DOF IMC controller showed itself capable of absorbing and rejecting these disturbances as well as control the DC-DC converter, adequately, in aid of the MPPT algorithm, and the simulation and experimental results corroborate this affirmation.

\section{References}

[1] D. C. Martins, F. R. Coelho, W. M. Santos, "Minicurso Técnicas de Rastreamento de Máxima Potência para Sistemas Fotovoltaicos: Revisão e Novas Propostas", in XI Congresso Brasileiro de Eletrônica de Potência (COBEP), 110 p., 2011.

[2] D. Maksimovic, S. Cuk, "Switching converters with wide DC conversion range", IEEE Transactions on Power Electronics, vol. 6, no.1, pp. 151-157, janeiro 1991.

[3] L. H. S. C. Barreto, Análise, projeto e desenvolvimento de conversores para a concepção de uma UPS online não isolada, Tese de Doutorado, Universidade Federal de Uberlândia - UFU, Uberlândia-MG, Brasil, 2003.

[4] Y. R. Novaes, A. Rufer, I. Barbi, "A New Quadratic, Three Level, DC/DC Converter Suitable for Fuel Cell
Applications", in Proc. Power Conversion Conference, pp. 601-607, 2007.

[5] R. Kadri, J. P. Glaubert, G. Champenois, M. Mostefai, "Performance Analysis of Transformerless Single Switch Quadratic Boost Converter for Grid Connected Photovoltaic Systems", in Proc. International Conference on Electrical Machines (ICEM), pp. 1-7, 2010.

[6] J. A. M. Saldaña, R. G. Quirino, J. L. Ramos, E. E. C. Gutierrez, M. G. O. Lopez, "Multiloop controller design for a quadratic boost converter", IET Electric Power Applications, vol. 1, no. 3, pp. 362-367, maio 2007.

[7] M. G. O. Lopez, J. L. Ramos, L. H. D. Saldierna, J. M. G. Ibarra, E. E. C. Gutierrez, "Current-mode control for a Quadratic Boost converter with a single switch", in Proc. Power Electronics Specialists Conference (PESC), pp. 2652-2657, 2007.

[8] J. L. Ramos, M. G. O. Lopez, L. H. D. Saldierna, J. A. M. Saldaña, "Switching regulator using a quadratic boost converter for wide DC conversion ratios", IET Power Electronics, vol. 2, no. 5, pp. 605-613, agosto 2009.

[9] M. H. Gomez, R. Ortega, F. L. Lagarrigue, O. Bethoux, G. Escobar, "Robust Adaptive PI Stabilization of a Quadratic Converter: Experimental Results", in Proc. IEEE International Symposium on Industrial Electronics (ISIE), pp. 2999-3004, 2010.

[10]P. Yang, J. Xu, G. Zhou, F. Zhang, "Analysis of sensorless peak current mode controlled quadratic boost converter", in Proc. IEEE International Symposium on Industrial Electronics (ISIE), pp. 200-204, 2012.

[11]P. Srithongchai, S. Kaitwanidvilai, "Robust FixedStructure Cascade Controller for a Quadratic Boost Converter", in Proc. International Multi Conference of Engineers and Computer Scientists (IMECS), pp. 1030-1033, 2010.

[12]J. L. Ramos, M. G. O. Lopez, L. H. D. Saldierna, "The Effect Of ESR of the Capacitors on Modeling of a Quadratic Boost Converter", in Proc. IEEE Workshop on Control and Modeling for Power Electronics (COMPEL), pp. 1-5, 2008.

[13]R. W. Erickson, D. Maksimóvic, Fundamentals of Power Electronics, Springer, 2 ${ }^{\text {a }}$ Edição, Nova Iorque, 2004.

[14]R. D. Middlebrook, S. Cuk, , "A General Unified Approach to Modelling Switching-Converter Power Stages", in Proc. Power Electronics Specialists Conference (PESC), pp. 1-6, 1976.

[15]C. Brosilow, B. Joseph, Techniques of Model-Based Control, Prentice Hall, $1^{\text {a }}$ Edição, Nova Iorque, 2002.

[16]E. N. Chaves, E. A. A. Coelho, H. T. M. Carvalho, L. C. de Freitas, L. C. Freitas, J. B. Vieira JR, "Projeto de Controlador Baseado no Modelo Interno Com 1 Grau de Liberdade Utilizado em Injeção de Potência Ativa na Rede Monofásica a Partir de Geração Fotovoltaica", Eletrônica de Potência, vol. 20, no. 2, pp. 172-184, maio 2015.

[17]M. Morari, F. Zafiriou, Robust Process Control, Prentice Hall, $1^{\text {a }}$ Edição, Nova Iorque, 1989. 